Acta Technologica Agriculturae 2

Nitra, Slovaca Universitas Agriculturae Nitriae, 2017, pp. 52-56

\title{
NON-ISOTHERMAL KINETIC ANALYSIS OF THE DEHYDROXYLATION OF KAOLINITE IN DYNAMIC AIR ATMOSPHERE
}

\author{
Tomáš ONDRO ${ }^{*}$, Tomáš HÚLAN ${ }^{1}$, Ivan VITÁZEK² \\ ${ }^{1}$ Constantine the Philosopher University in Nitra, Slovakia \\ ${ }^{2}$ Slovak University of Agriculture in Nitra, Slovakia
}

\begin{abstract}
A non-isothermal kinetic analysis of kaolinite dehydroxylation was carried out using thermogravimetric analysis on powder samples with heating rates from 1 to $30^{\circ} \mathrm{C} \cdot \mathrm{min}^{-1}$ in a dynamic air atmosphere. The mechanism of the reaction, values of overall activation energy and pre-exponential factor were determined from a series of thermogravimetric experiments by the CoatsRedfern method. The results show that the dehydroxylation of kaolinite is controlled by the rate of the third-order reaction (F3) with the mean values of overall activation energy $\left(E_{A}\right) 255 \mathrm{~kJ} \cdot \mathrm{mol}^{-1}$ and pre-exponential factor $(A) 25.56 \times 10^{14} \mathrm{~s}^{-1}$.
\end{abstract}

Keywords: dehydroxylation; kaolinite; kinetic analysis; overall activation energy; thermogravimetry

Kaolins are materials broadly used for ceramics production and in agriculture. Along with that, they are important for the paper, rubber and plastics industries. However, for some applications, kaolins are transformed to another form by heating. Metakaolins (dehydroxylated kaolins) are, for example, utilized in the food industry and ceramics production (Konta, 1995; Prasad et al., 1991; Ptáček et al., 2010d). For such applications, it is important to study the phase changes of this type of clay during thermal treatment.

The main component of kaolin is kaolinite $\left(\mathrm{Al}_{2} \mathrm{O}_{3} \cdot 2 \mathrm{SiO}_{2}\right.$. $2 \mathrm{H}_{2} \mathrm{O}$ ), which is a $1: 1$ layered phyllosilicate. It consists of repeated tetrahedron-octahedron (T-O) layers, while the apices of these layers are occupied by oxygen and hydroxyl groups. The crystal system of kaolinite is triclinic, the space group of which is $\mathrm{P} 1$ and the values of the lattice parameters are $a=5.155 \AA, b=8.95 \AA, c=7.40 \AA, \alpha=91.68^{\circ}, \beta=104.87^{\circ}$ and $\gamma=89.9^{\circ}$ (Iqbal and Lee, 2000).

During heating, in the temperature interval of 450 $700^{\circ} \mathrm{C}$, thermal decomposition of kaolinite (dehydroxylation) occurs and can be described according to the equation (Heide and Földvari, 2006; Ondruška et al., 2015; Ptáček et al., 2010b, 2011):

$$
\mathrm{Al}_{2} \mathrm{O}_{3} \cdot 2 \mathrm{SiO}_{2} \cdot 2 \mathrm{H}_{2} \mathrm{O} \rightarrow \mathrm{Al}_{2} \mathrm{O}_{3} \cdot 2 \mathrm{SiO}_{2}+2 \mathrm{H}_{2} \mathrm{O}
$$

It is often written that the thermal transformation of kaolinite to amorphous aluminosilicate (metakaolinite) can be divided into two steps (Heide and Földvari, 2006; Ptáček et al., 2010a). Firstly, the chemically bound water leaves the crystal lattice and destruction of the kaolinite sheet structure proceeds (delamination). The second step is the formation of metakaolinite.

The kinetics of kaolinite dehydroxylation has been studied often and the most frequently published values of $E_{A}$ and $A$ are in the interval of $140-250 \mathrm{~kJ} \cdot \mathrm{mol}^{-1}$ and $10^{8}-10^{14} \mathrm{~s}^{-1}$ respectively (Nahdi et al., 2002; Ptáček et al., 2010a, 2011, 2013b; Saikia et al., 2002; Traoré et al., 2006). The variability of the values of these parameters depends on particle size, structural disorder, experimental conditions, etc. (Drits and Derkowski, 2015; Ptáček et al., 2011).

Extensive attention has also been paid to the mechanism of kaolinite dehydroxylation. Ptáček et al. (2010a, 2010d) have shown that the dehydroxylation process under nonisothermal conditions in a dynamic argon atmosphere is controlled by the third-order chemical reaction (F3).

However, a study carried out using isothermal thermogravimetric analysis (Ptáček et al., 2010c) shows that the dehydroxylation of kaolinite is controlled by the secondorder chemical reaction (F2) if the temperature is lower than $410^{\circ} \mathrm{C}$. For the higher temperatures, the authors stated that this reaction is controlled by the third-order reaction (F3).

In the last decade, an inert atmosphere has often been used to obtain data for kinetic analysis. However, an air atmosphere is more realistic for technological applications. The aim of this study is the kinetic analysis of kaolinite dehydroxylation in a dynamic atmosphere of dry air. From the results of the thermogravimetric (TG) analysis, the kinetic parameters are derived using the Coats-Redfern method and compared with values in the literature obtained from measurements in an inert atmosphere.

\section{Kinetic analysis}

The rate of reaction is commonly described by the following equation (Starink, 2003; Sbirrazzuoli et al., 2009; Vyazovkin et al., 2011):

$$
\frac{\mathrm{d} \alpha}{\mathrm{d} t}=A \exp \left(-\frac{E}{R T}\right) f(\alpha)
$$


where:

$$
\begin{array}{ll}
\alpha & - \text { the reaction extent } \\
t & - \text { time } \\
T & - \text { the absolute temperature } \\
f(\alpha) & - \text { a reaction model } \\
R & - \text { the universal gas constant } \\
A & - \text { the pre-exponential factor } \\
E & - \text { the activation energy }
\end{array}
$$

The reaction extent can be calculated from the TG measurements as (Dairo et al., 2015; Vyazovkin et al., 2014):

$$
\alpha=\frac{m_{i}-m}{m_{i}-m_{f}}
$$

where:

$m$ - the current value of mass loss

$m_{i}$ - the initial value of mass loss

$m_{f}-$ the final value of mass loss

\section{Coats-Redfern method}

For determination of the kinetic parameters, the Coats-Redfern method was used. It is based on the following equation (Coats and Redfern, 1964):

$$
\ln \frac{g(\alpha)}{T^{2}}=\left[\ln \frac{A R}{\beta E_{A}}\left(1-\frac{2 R T}{E_{A}}\right)\right]-\frac{E_{A}}{R T} \cong \ln \left(\frac{A R}{\beta E_{A}}\right)-\frac{E_{A}}{R T}
$$

where:

$g(\alpha)$ - an integral form of $f(\alpha)$

$\beta$ - a heating rate

For a proper reaction model $g(\alpha)$, the values of the overall activation energy $E_{A}$ are determined from the slope of the plot of the left-hand side of Eq. (4) vs. $T^{-1}$. The pre-exponential factor can be calculated from the first term on the right-hand side of Eq. (4).

\section{Samples and methods}

For the study of kaolinite dehydroxylation, washed kaolin Sedlec la was used. The producer guarantees at least 90 wt.\% content of kaolinite with impurities of mica group minerals and quartz. However, more realistic is a $\sim 86$ wt. $\%$ content

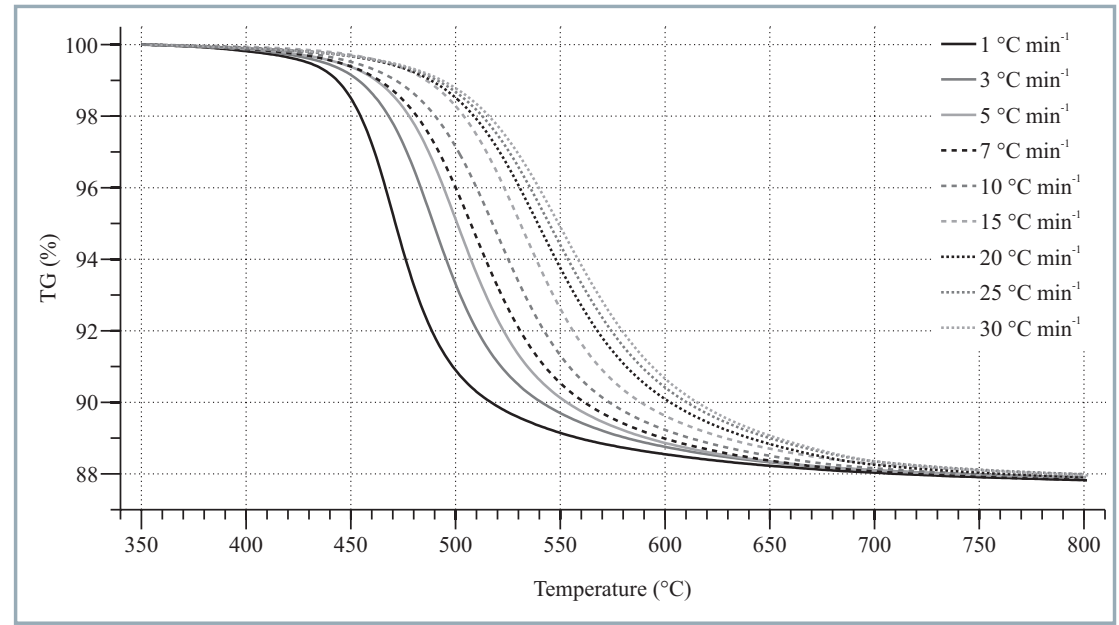

Fig. 1 The results of non-isothermal TG analysis of Sedlec kaolin in the temperature range of $350-800^{\circ} \mathrm{C}$ of kaolinite in the material (see below). For the TG analysis, the raw kaolin pellets were crushed and milled in a planetary ball mill (Retsch PM100) and then sieved in order to obtain grains with size less than $100 \mu \mathrm{m}$.

A thermogravimetric analyser Mettler Toledo TGA/SDTA $851^{\mathrm{e}}$ was used to obtain the TG data in a dynamic atmosphere of dry air with a flow rate $40 \mathrm{ml} \cdot \mathrm{min}^{-1}$ in the temperature range of $25-900{ }^{\circ} \mathrm{C}$. The measurements were carried out on samples with mass $\sim 30 \mathrm{mg}$ in $\mathrm{Al}_{2} \mathrm{O}_{3}$ crucibles with heating rates of $1,3,5,7,10,15,20,25$, and $30{ }^{\circ} \mathrm{C} \cdot \mathrm{min}^{-1}$.

\section{Results and discussion}

The kinetic analysis of the dehydroxylation of kaolinite was carried out in the temperature range of $350-800{ }^{\circ} \mathrm{C}$. The results of TG analysis with different heating rates for this temperature range are shown in Fig. 1. It is observed that the reaction is shifted towards the higher temperatures if higher heating rates are used, but the shape of the curves is retained. The mean mass loss due to dehydroxylation of kaolinite was (12.04 $\pm 0.13) \%$. Considering the theoretical mass loss of $13.96 \%$ (Ptáček et al., 2010a), and neglecting the influence of impurities, the calculated content of kaolinite in the material was $(86.25$ $\pm 0.93)$ wt. $\%$.

For parameterization of the dehydroxylation process, the CoatsRedfern method (Eq. (4)) was used. The kinetic parameters were calculated for a reaction extent $0.1 \leq \alpha \leq 0.9$. The results of linear regression show that the best model for the dehydroxylation of kaolinite, which represents the measured data most accurately, is the third-order chemical reaction (F3). The values of $R^{2}$ calculated for different reaction models are listed in Table 1.

The maximum value of $R^{2}$ does not necessarily indicate the most probable reaction model (Vyazovkin and Wight, 1999). For this reason, we used the Fisher $F$-test at a $95 \%$ confidence level. The results imply that the $\mathrm{F} 3$ reaction model yields a significantly better fit than the other models. Another result that can be drawn from Table 1 is that the value of $R^{2}$ increases with the heating rate. This is in accordance with 
Table 1 Determination of the most probable mechanism of kaolinite dehydroxylation based on calculation of $R^{2}$

\begin{tabular}{|c|c|c|c|c|c|c|c|c|c|c|}
\hline \multirow{2}{*}{ Function name } & \multirow{2}{*}{ Code } & \multicolumn{9}{|c|}{ Heating rate $\left({ }^{\circ} \mathrm{C} \cdot \mathrm{min}^{-1}\right)$} \\
\hline & & 1 & 3 & 5 & 7 & 10 & 15 & 20 & 25 & 30 \\
\hline One-third order & $\mathrm{F} 1 / 3$ & 0.7307 & 0.7932 & 0.8150 & 0.8368 & 0.8510 & 0.8546 & 0.8643 & 0.8805 & 0.8846 \\
\hline Three-quarters order & $\mathrm{F} 3 / 4$ & 0.8082 & 0.8590 & 0.8767 & 0.8931 & 0.9045 & 0.9069 & 0.9161 & 0.9282 & 0.9315 \\
\hline One and a half order & $\mathrm{F} 3 / 2$ & 0.8977 & 0.9324 & 0.9441 & 0.9541 & 0.9612 & 0.9625 & 0.9693 & 0.9760 & 0.9780 \\
\hline Second order & $\mathrm{F} 2$ & 0.9310 & 0.9584 & 0.9674 & 0.9747 & 0.9797 & 0.9806 & 0.9857 & 0.9900 & 0.9914 \\
\hline Third order & F3 & 0.9632 & 0.9820 & 0.9876 & 0.9919 & 0.9944 & 0.9949 & 0.9975 & 0.9990 & 0.9994 \\
\hline Mampel power law & $\mathrm{P} 3 / 2$ & 0.7009 & 0.7637 & 0.7862 & 0.8091 & 0.8237 & 0.8272 & 0.8375 & 0.8548 & 0.8590 \\
\hline Mampel power law & $\mathrm{P} 1 / 2$ & 0.4416 & 0.5506 & 0.5847 & 0.6322 & 0.6545 & 0.6679 & 0.6633 & 0.6954 & 0.7007 \\
\hline Mampel power law & $\mathrm{P} 1 / 3$ & 0.1474 & 0.2635 & 0.2960 & 0.3669 & 0.3903 & 0.4208 & 0.3719 & 0.4149 & 0.4165 \\
\hline Mampel power law & $\mathrm{P} 1 / 4$ & 0.0026 & 0.0093 & 0.0140 & 0.0465 & 0.0519 & 0.0806 & 0.0215 & 0.0340 & 0.0298 \\
\hline Exponential law & E1 & 0.0000 & 0.0000 & 0.0000 & 0.0000 & 0.0000 & 0.0000 & 0.0000 & 0.0000 & 0.0000 \\
\hline Avrami-Erofeev eq. & F1 & 0.8445 & 0.8892 & 0.9047 & 0.9185 & 0.9283 & 0.9302 & 0.9388 & 0.9488 & 0.9516 \\
\hline Avrami-Erofeev eq. & $A 3 / 2$ & 0.8201 & 0.8719 & 0.8894 & 0.9056 & 0.9168 & 0.9193 & 0.9282 & 0.9398 & 0.9429 \\
\hline Avrami-Erofeev eq. & $\mathrm{A} 2$ & 0.7903 & 0.8507 & 0.8705 & 0.8896 & 0.9026 & 0.9059 & 0.9147 & 0.9283 & 0.9318 \\
\hline Avrami-Erofeev eq. & A3 & 0.7078 & 0.7912 & 0.8168 & 0.8442 & 0.8619 & 0.8678 & 0.8749 & 0.8941 & 0.8985 \\
\hline Avrami-Erofeev eq. & A4 & 0.5803 & 0.6957 & 0.7285 & 0.7692 & 0.7937 & 0.8049 & 0.8044 & 0.8323 & 0.8375 \\
\hline Prout-Tomkins eq. & $\mathrm{Au}$ & 0.5170 & 0.4905 & 0.4494 & 0.4326 & 0.4291 & 0.4302 & 0.3997 & 0.3995 & 0.3369 \\
\hline Power law & $\mathrm{R} 1$ & 0.6521 & 0.7250 & 0.7503 & 0.7777 & 0.7940 & 0.7990 & 0.8080 & 0.8281 & 0.8327 \\
\hline Power law & $\mathrm{R} 2$ & 0.7644 & 0.8220 & 0.8421 & 0.8615 & 0.8746 & 0.8776 & 0.8873 & 0.9018 & 0.9055 \\
\hline Power law & R3 & 0.7945 & 0.8475 & 0.8659 & 0.8833 & 0.8952 & 0.8978 & 0.9073 & 0.9201 & 0.9235 \\
\hline Parabolic law & D1 & 0.7220 & 0.7803 & 0.8017 & 0.8226 & 0.8363 & 0.8393 & 0.8500 & 0.8660 & 0.8701 \\
\hline Valensi eq. & D2 & 0.7717 & 0.8239 & 0.8429 & 0.8608 & 0.8731 & 0.8755 & 0.8857 & 0.8995 & 0.9031 \\
\hline Jander eq. & D3 & 0.8254 & 0.8703 & 0.8864 & 0.9009 & 0.9112 & 0.9130 & 0.9223 & 0.9333 & 0.9363 \\
\hline Ginstling-Brounstein eq. & D4 & 0.7920 & 0.8416 & 0.8595 & 0.8761 & 0.8877 & 0.8899 & 0.8998 & 0.9125 & 0.9159 \\
\hline Zhuravlev eq. & D5 & 0.8955 & 0.9290 & 0.9406 & 0.9505 & 0.9575 & 0.9587 & 0.9657 & 0.9726 & 0.9746 \\
\hline Anti-Jander eq. & D6 & 0.6980 & 0.7593 & 0.7817 & 0.8039 & 0.8185 & 0.8217 & 0.8323 & 0.8494 & 0.8536 \\
\hline Anti-Ginstling-Brounstein eq. & D7 & 0.7063 & 0.7666 & 0.7886 & 0.8104 & 0.8247 & 0.8278 & 0.8384 & 0.8552 & 0.8593 \\
\hline Anti-Zhuravlev eq. & D8 & 0.6688 & 0.7337 & 0.7571 & 0.7811 & 0.7966 & 0.8002 & 0.8104 & 0.8288 & 0.8331 \\
\hline
\end{tabular}

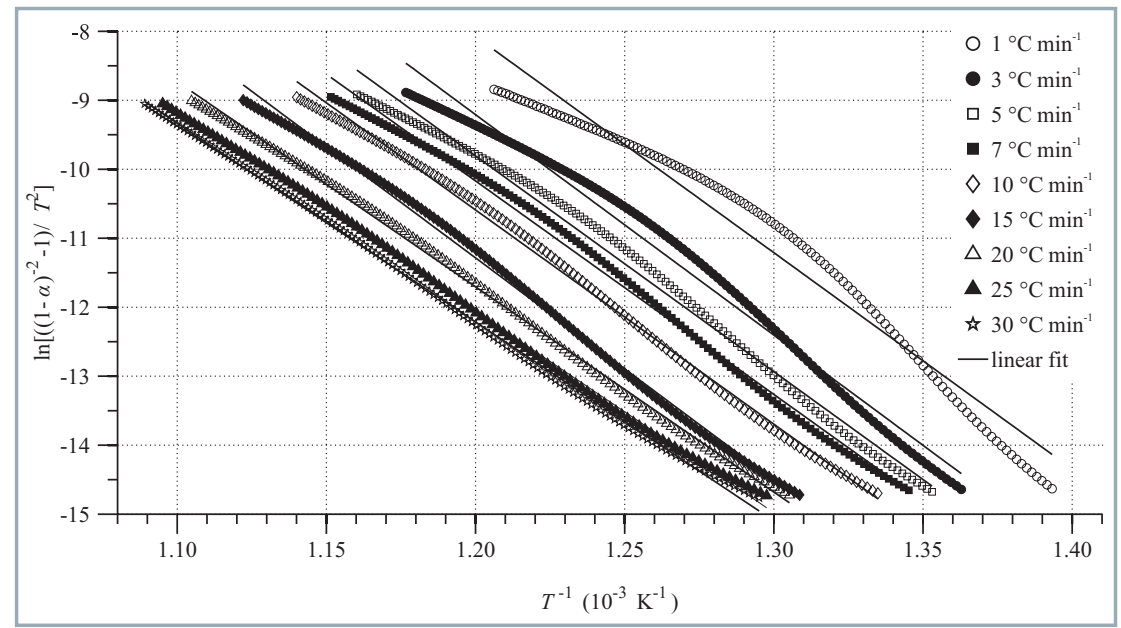

Fig. 2 Determination of $E_{\mathrm{A}}$ and $A$ using the most probable reaction model, $\mathrm{F} 3$ the results published by Ptáček et al. (2010a), where the authors ascribed such behaviour to the changing model of dehydroxylation from $\mathrm{F} 2$ to $\mathrm{F} 3$ if the temperature is higher than $\sim 410^{\circ} \mathrm{C}$.

The overall activation energy $E_{A}$ and pre-exponential factor $A$ were determined from the plot of the lefthand side of Eq. (4) vs. $T^{-1}$ for the most probable reaction model, F3 (cf. Fig. 2).

The values of overall activation energy and pre-exponential factor determined for different heating rates within conversion degree $0.1 \leq \alpha \leq 0.9$ are listed in Table 2.

The results show that the values of overall activation energy and preexponential factor are slightly higher 
Table 2 Kinetic parameters determined for different heating rates using reaction model F3 for conversion degree $0.1 \leq \alpha \leq 0.9$

\begin{tabular}{|c|c|c|c|c|c|}
\hline $\begin{array}{c}\beta \\
\left({ }^{\circ} \mathrm{C} \cdot \mathrm{min}^{-1}\right)\end{array}$ & $\begin{array}{c}E_{A} \\
\left(\mathrm{~kJ} \cdot \mathrm{mol}^{-1}\right)\end{array}$ & $\begin{array}{c}A \\
\left(10^{14} \mathrm{~s}^{-1}\right)\end{array}$ & $\begin{array}{c}\beta \\
\left({ }^{\circ} \mathrm{C} \cdot \mathrm{min}^{-1}\right)\end{array}$ & $\begin{array}{c}E_{A} \\
\left(\mathrm{~kJ} \cdot \mathrm{mol}^{-1}\right)\end{array}$ & $\begin{array}{c}A \\
\left(10^{14} \mathrm{~s}^{-1}\right)\end{array}$ \\
\hline \hline 1 & $260 \pm 4$ & 29.77 & 15 & $268 \pm 1$ & 62.25 \\
\hline 3 & $265 \pm 3$ & 66.65 & 20 & $248 \pm 1$ & 2.72 \\
\hline 5 & $260 \pm 2$ & 27.52 & 25 & $243 \pm 1$ & 1.24 \\
\hline 7 & $257 \pm 2$ & 18.67 & 30 & $-240 \pm 1$ & 0.78 \\
\hline 10 & $258 \pm 1$ & 20.44 & - & - \\
\hline
\end{tabular}

than the most frequently published values (Nahdi et al., 2002; Ptáček et al., 2010a, 2011, 2013b; Saikia et al., 2002; Traoré et al., 2006). On the other hand, the determined reaction model, F3, corresponds with the previously published results under non-isothermal conditions in the inert atmosphere (Ptáček et al., 2010a, 2010d). Thus, it can be concluded that under non-isothermal conditions, there is no significant difference between the kinetic parameters of kaolinite dehydroxylation obtained in the inert and air atmosphere.

\section{Conclusions}

The thermal decomposition of kaolinite was studied using non-isothermal thermogravimetric analysis in a dynamic air atmosphere. A kinetic analysis was carried out using the Coats-Redfern method from the results of the TG analysis in the temperature range of $350-800{ }^{\circ} \mathrm{C}$. The summary of the results is as follows:

- The third-order chemical reaction (F3) was evaluated as the most probable mechanism for dehydroxylation of kaolinite.

- The mean values of overall activation energy and pre-exponential factor are $255 \mathrm{~kJ} \cdot \mathrm{mol}^{-1}$ and $25.56 \times$ $10^{14} \mathrm{~s}^{-1}$, respectively.

- The kinetic parameters obtained in the air atmosphere do not differ significantly from the ones published in the literature, which were obtained in the inert atmosphere.

\section{Acknowledgements}

This work was supported by the grant UGA VII/14/2017 and VEGA 1/0337/15.

\section{References}

COATS, A. W. - REDFERN, J. P. 1964. Kinetic parameters from thermogravimetric data. In Nature, vol. 201, pp. 68-69.

DAIRO, O. U. - ADERINLEWO, A. A. - ADEOSUN, O. J. - OLA, I. A. SALAUDEEN, T. 2015. Solar drying kinetics of cassava slices in a mixed flow dryer. In Acta Technologica Agriculturae, vol. 18, no. 4, pp. 102-107.

DRITS, V. A. - DERKOWSKI, A. 2015. Kinetic behavior of partially dehydroxylated kaolinite. In Mineralogical Society of America, vol. 100, pp. 883-896.

HEIDE, K. - FÖLDVARI, M. 2006. High temperature mass spectrometric gas-release studies of kaolinite $\mathrm{Al}_{2}\left[\mathrm{Si}_{2} \mathrm{O}_{5}(\mathrm{OH})_{4}\right]$ decomposition. In Thermochimica Acta, vol. 446, pp. 106-112.
IQBAL, Y. - LEE, W.E. 2000. Microstructural evolution in triaxial porcelain. In Journal of the American Ceramic Society, vol. 83, pp. 3121-3127

KONTA, J. 1995. Clay and man: clay raw materials in the service of man. In Applied Clay Science, vol. 10, pp. 275-335.

NAHDI, K. - LLEWELLYN, P. - ROUQUÉROL, F. - ROUQUÉROL, J. ARIGUIB, N. - AYEDI, M. 2002. Controlled rate thermal analysis of kaolinite dehydroxylation: effect of water vapour pressure on the mechanism. In Thermochimica Acta, vol. 390, pp. 123-132.

ONDRUŠKA, J. - ŠTUBŇA, I. - TRNOVCOVÁ, V. - MEDVEĎ, I. KALJUVEE, T. 2015. Polarization and depolarization currents in kaolin. In Applied Clay Science, vol. 114, pp. 157-160.

PRASAD, M. S. - REID, K. J. - MURRAY, H. H. 1991. Kaolin: processing, properties and applications. In Applied Clay Science, vol. 6, pp. 87-119.

PTÁČEK, P. - KUBÁTOVÁ, D. - HAVLICA, J. - BRANDŠTETR, J. ŠOUKAL, F. - OPRAVIL, T. 2010a. The non-isothermal kinetic analysis of the thermal decomposition of kaolinite by thermogravimetric analysis. In Powder Technology, vol. 204, pp. 222-227.

PTÁČEK, P. - ŠOUKAL, P. - OPRAVIL, T. - NOSKOVÁ, M. - HAVLICA J. - BRANDŠTETR, J. 2010b. The kinetics of Al-Si spinel phase crystallization from calcined kaolin. In Journal of Solid State Chemistry, vol. 183, pp. 2565-2569.

PTÁČEK, P. - KUBÁTOVÁ, D. - HAVLICA, J. - BRANDŠTETR, J. ŠOUKAL, F. - OPRAVIL, T. 2010c. Isothermal kinetic analysis of the thermal decomposition of kaolinite: The thermogravimetric study. In Thermochimica Acta, vol. 501, pp. 24-29.

PTÁČEK, P. - ŠOUKAL, P. - OPRAVIL, T. - NOSKOVÁ, M. - HAVLICA J. - BRANDŠTETR, J. 2010d. The non-isothermal kinetics analysis of the thermal decomposition of kaolinite by Effluent Gas Analysis technique. In Powder Technology, vol. 203, pp. 272-276.

PTÁČEK, P. - ŠOUKAL, P. - OPRAVIL, T. - HAVLICA, J. - BRANDŠTETR, J. 2011. The kinetic analysis of the thermal decomposition of kaolinite by DTG technique. In Powder Technology, vol. 208, pp. 20-25.

PTÁČEK, P. - ŠOUKAL, F. - OPRAVIL, T. - HAVLICA, J. - BRANDŠTETR, J. 2013a. Crystallization of spinel phase from metakaoline: The nonisothermal thermodilatometric CRH study. In Powder Technology, vol. 243, pp. 40-45

PTÁČEK, P. - OPRAVIL, T. - ŠOUKAL, F. - WASSERBAUER, F. MÁSILKO, J. - BARÁČEK, J. 2013b. The influence of structure order on the kinetics of dehydroxylation of kaolinite. In Journal of the European Ceramic Society, vol. 33, pp. 2793-2799.

SAIKIA, N. - SENGUPTA, P. - GOGOI, P. K. - BORTHAKUR, P. C. 2002. Kinetics of dehydroxylation of kaolin in presence of oil field effluent treatment plant sludge. In Applied Clay Science, vol. 22, pp. 93-102.

SBIRRAZZUOLI, N. - VINCENT, L. - MIJA, A. - GUIGO, N. 2009. Integral, differential and advanced isoconversional methods: Complex mechanisms and isothermal predicted conversion-time curves. In Chemometrics and Intelligent Laboratory Systems, vol. 96, pp. 219-226. 
STARINK, M. J. 2003. The determination of activation energy from linear heating rate experiments: a comparison of the accuracy of isoconversion methods. In Thermochimica Acta, vol. 404, pp. 163-176.

TRAORÉ, K. - GRIDI-BENNADJI, F. - BLANCHART, P. 2006. Significance of kinetic theories on the recrystallization of kaolinite. In Thermochimica Acta, vol. 451, pp. 99-104.

VYAZOVKIN, S. - WIGHT, Ch. A. 1999. Model-free and model-fitting approaches to kinetic analysis of isothermal and nonisothermal data. In Thermochimica Acta, vol. 340-341, pp. 53-68.
VYAZOVKIN, S. - BURNHAM, A. K. - CRIADO, J. M. - PÉREZMAQUEDA, L. A. - POPESCU, C. - SBIRRAZZUOLI, N. 2011. ICTAC kinetics committee recommendations for performing kinetic computations on thermal analysis data. In Thermochimica Acta, vol. 520, pp. 1-19.

VYAZOVKIN, S. - CHRISSAFIS, K. - DI LORENZO, M. L. - KOGA, N. - PIJOLAT, M. - RODUIT, M. - SBIRRAZZUOLI, N. - SUÑOL, J. J. 2014. ICTAC Kinetics Committee recommendations for collecting experimental thermal analysis data for kinetic computations. In Thermochimica Acta, vol. 590, pp. 1-23. 